\title{
A REFORMA DA EDUCAÇÃO PROFISSIONAL DA DÉCADA DE 1990 NA ESCOLA TÉCNICA FEDERAL DE SANTA CATARINA/UNIDADE FLORIANÓPOLIS
}

\author{
J. E. COELHO \\ Instituto Federal de Santa Catarina \\ jeller@ifsc.edu.br
}

Artigo submetido em fevereiro/2014 e aceito em março/2014

\section{RESUMO}

Este texto objetiva compreender como se deu o processo de desvinculação dos ensinos médio e técnico na Unidade Florianópolis da Escola Técnica Federal de Santa Catarina, a partir da implementação do Decreto № 2.208/97. Esse decreto compôs a estrutura jurídica e normativa usada pelo governo federal para concretizar, na segunda metade da década de 1990, a Reforma da Educação Profissional, oficializando a dicotomia entre formação geral e formação profissional. Pela leitura de ordenamentos legais e de registros institucionais, bem como por meio de entrevistas semiestruturadas com educadores envolvidos diretamente com a reforma, conclui-se que, apesar da imposição do aparato legal, a instituição vivenciou um processo particular de materialização da reforma em função de suas singularidades. Inicialmente, de resistência e, posteriormente, de adesão obrigatória, que resultou na desintegração dos cursos técnicos em relação ao ensino médio, o que impactou a identidade institucional, tendo em vista sua histórica experiência no desenvolvimento de cursos técnicos integrados ao ensino médio.

PALAVRAS-CHAVE: Reforma da educação profissional; Decreto № 2.208/97; Cursos técnicos.

\section{PROFESSIONAL EDUCATION REFORM OF THE 1990s IN FEDERAL TECHNICAL SCHOOL OF SANTA CATARINA / UNIT FLORIANÓPOLIS}

\begin{abstract}
This paper aims to understand how was the process of decoupling of secondary and technical teachings in Florianópolis Unit of the Federal Technical School of Santa Catarina, after the implementation of Decree No. $2.208 / 97$. This decree composed the legal and regulatory framework used by the federal government to finish the second half of the 1990s, the Reform of Vocational Education, formalizing the dichotomy between general education and vocational training. By reading legal frameworks and institutional records, as well as through semi-structured interviews with educators directly
\end{abstract}

involved in the reform, it is concluded that, despite the imposition of the legal apparatus, the institution experienced a particular embodiment of the process of reform in terms of their singularities. Initially, resistance and later compulsory membership, which resulted in the disintegration of technical courses in relation to secondary education, which impacted the institutional identity, considering his historical experience in developing integrated into the high school technical courses.

KEYWORDS: Reform of professional education; Decree No. 2.208/97; technical courses. 


\section{INTRODUÇÃO}

A década de 1990 foi fortemente marcada por um cenário complexo, de transformações no âmbito social, econômico e político, predominando as desigualdades sociais. Nesse contexto, o conjunto de políticas sociais e, dentre elas, as educacionais, foi ajustado tendo em vista a adequação das economias nacionais e locais às demandas da "economia global", culminando com um processo de enfraquecimento da atuação do Estado nos processos econômicos. Para Frigotto,

O ideário que se afirma de todas as formas, normalmente mediante as poderosas redes de informação, é o de que estamos iniciando um novo tempo para o qual devemos nos ajustar irreversivelmente - o tempo da globalização, da modernidade competitiva, de reestruturação produtiva e de reengenharia - do qual estamos defasados e devemos nos ajustar (2001, p.27).

Nesse contexto, educação e formação do trabalhador ganharam centralidade no discurso do sistema como a fórmula capaz de diminuir a pobreza, inculcando a noção de que o desenvolvimento linear da educação e capacitação dos jovens e adultos levaria diretamente à garantia de emprego e à redução da miséria, desconsiderando condicionantes econômicos e políticos.

A interferência das agências multilaterais, dentre elas o Banco Mundial (BM), no tocante às políticas educacionais internas intensificou-se de forma a transformar o panorama educacional dos países em desenvolvimento. De forma geral, o BM ao conceder assistência e empréstimos aos países apresentava cobranças para além das relacionadas aos projetos, sempre direcionadas ao ajuste da economia, provocando transformações em questões internas dos países, inclusive em suas legislações nacionais.

Como ressalta Lima Filho (2002, p. 277),

na assimilação e implementação dessas políticas nos países periféricos [...] ocorrem processos políticos diversos em que as elites dominantes nacionais se articulam ao capital internacional, de forma que a consecução das orientações de reformas educacionais se dá por mecanismos de adequação variados, como por exemplo, o estabelecimento de condicionalidades para a concessão de financiamentos internacionais e critérios de utilização dos recursos.

As investigações e diagnósticos realizados pelo BM e outras agências multilaterais sobre a situação da educação atuaram determinantemente na organização da educação brasileira, não só fixando condicionantes para financiamentos de programas educativos, como também pelos preceitos revelados no aparato legal e sua real aplicação nas reformas impostas por esses organismos internacionais (LIMA FILHO, 2002).

Segundo Ramos, [...] uma aliança entre os organismos internacionais e o poder local difundiu a ideologia de que os indivíduos, os setores sociais e os países devem-se tornar competitivamente adequados às exigências do mercado. (RAMOS, 2005, p. 32). 


\section{A EDUCAÇÃO PARA O MERCADO}

O BM atribuiu à educação brasileira características econômicas, fundamentadas, sobretudo, em indicadores financeiros, considerando fortemente seu custo-benefício. A retração do papel do Estado e a redução dos gastos com o ensino tornaram-se decisivos para o alcance de seus objetivos, impondo à educação a lógica da eficiência, funcionalidade e racionalização na aplicação dos recursos, com gestão desempenhada por métodos empresariais ${ }^{1}$. Passaram a imperar a urgência e a funcionalidade em relação à formação de um novo trabalhador, polivalente e adaptável ao mercado num mundo do trabalho assinalado pelo desemprego e trabalho precarizado.

Assim, foram efetivadas as reformas educacionais que, segundo discurso dominante, seriam indispensáveis à empregabilidade e à competitividade entre os países, mas que para Lima Filho (2003, p.75), significou "a ocultação, tanto das fontes de subdesenvolvimento, desemprego e pobreza dos países periféricos, quanto dos interesses dos países centrais."

$\mathrm{O}$ aparato jurídico sustentador da Reforma teve como principal preceito o Decreto $\mathrm{N}^{\circ}$ 2.208/97, cuja característica fundamental foi a desvinculação dos ensinos médio e técnico, reforçando o dualismo entre a formação geral e a formação profissional. Para garantir a aceitação da reforma o governo federal utilizou o Programa de Expansão da Educação Profissional (PROEP), fruto do acordo com o Banco Interamericano de Desenvolvimento (BID), principal agência financiadora da reforma da educação profissional. O PROEP envolveu um montante de 500 milhões de dólares de 1997 a 2003. Desse total, 250 milhões viriam de empréstimo junto a esse banco e os outros 250 milhões do orçamento da União (MEC), bem como do Fundo de Amparo ao Trabalhador (LIMA FILHO, 2002).

Além da desvinculação entre formação geral e técnica, os currículos dos cursos técnicos passaram a ser desenvolvidos sob o conceito de competências, com vistas à formação de técnicos com um perfil profissional pretensamente adequado às constantes transformações do mercado de trabalho. O conceito de competência profissional definido na Resolução N 04/99 refere-se à “[...] capacidade de articular, mobilizar e colocar em ação valores, conhecimentos e habilidades necessários para o desempenho eficiente e eficaz de atividades requeridas pela natureza do trabalho" (BRASIL, 1999), vinculada à autonomia do trabalhador ante as transformações nas relações de produção.

Diferentemente de uma concepção de formação que possibilite ao educando estabelecer relações, desenvolver uma compreensão e leitura de mundo e de sociedade mais crítica e reflexiva, sem a utilização meramente utilitarista dos conhecimentos acumulados pela humanidade, a efetivação da noção de competência no desenvolvimento de um currículo de formação profissional, para Ramos (2001, p. 154) “[...] apresenta o risco de se fazer um recorte restrito do que deve ser ensinado, limitando-se à dimensão instrumental e, assim, empobrecendo e desagregando a formação, por atrelar essa dimensão a tarefas e desempenhos específicos, prescritos e observáveis."

\footnotetext{
${ }^{1}$ Qualidade, excelência, produtividade, competência, eficácia e eficiência foram alguns conceitos incorporados às ações educativas a partir da lógica empresarial assumida pela educação pública no contexto da reforma da educação profissional.
} 
O Decreto $N^{\circ} 2.208 / 97$ estabeleceu que a educação profissional fosse processada em três níveis: Básico, destinado à qualificação e reprofissionalização de trabalhadores, independente de escolaridade prévia; Técnico, para alunos matriculados ou egressos do ensino médio; e Tecnológico, correspondente a cursos de nível superior na área tecnológica, para egressos do ensino médio e técnico (BRASIL, 1997).

Mais do que arraigar a fragmentação entre educação geral e técnica, essa reforma provocou significativa diminuição de vagas na Rede Federal, uma vez que por meio da Portaria $\mathrm{N}^{\circ}$ $646 / 97$, suas instituições ficaram autorizadas a ofertar a partir de 1998, para o desenvolvimento do ensino médio, um máximo $50 \%$ do quantitativo do número de vagas disponibilizadas aos cursos técnicos em 1997.

Embora tenha se desenvolvido importante embate, com fortes críticas e manifestações de entidades ligadas à educação no combate aos preceitos da reforma, sobretudo de trabalhadores da educação e estudantes, reivindicando a conexão entre formação acadêmica e profissional, verificou-se que no quadro de dirigentes das instituições escolares "[...] a resistência cedeu lugar, por parte da maioria dos dirigentes, à adesão, à acomodação ou a um consentimento forçado, [...] o que prevaleceu foi a adesão dos dirigentes ou a acomodação passiva interna." (FRIGOTTO e CIAVATTA, 2006, p. 350).

Porém, em face da complexidade que abrange uma reforma educacional, há que se ponderar os meandros que envolvem diferentes processos de mediações entre a concepção da reforma e sua materialização nos espaços educativos. Para Lima Filho,

Existe, portanto, em cada instituição concreta, um processo de mediações que expressa as dinâmicas de aceitação e resistências internas e externas à reforma educacional em estudo. Tal processo é decorrente das características e história de cada instituição educacional e da interação e correlação de forças de seus diversos segmentos; da inserção da instituição na sociedade e sua relação com a disputa de projetos sociais diversos; das influências de grupos econômicos e setores empresariais nacionais, regionais e locais, entre outros. (LIMA FILHO, 2002, p. 282-283).

\section{A REFORMA NA UNIDADE FLORIANÓPOLIS DA ETF/SC}

A Reforma da Educação Profissional interrompeu uma proposta de ensino solidificada na ETF/SC, marcada pela formação integral dos profissionais egressos e caracterizada pela integração curricular entre formação propedêutica e formação profissional. Através dessa reforma, que aprofundou o afastamento entre a cultura escolar e a cultura do trabalho, o MEC desvirtuou a configuração do ensino técnico desenvolvido até então, não apenas na ETF-SC, mas no conjunto de instituições que compunham a Rede Federal.

[...] A adoção de tal medida representaria o abandono da experiência pela qual as escolas técnicas federais e centros federais de educação tecnológica eram reconhecidos socialmente como instituições educacionais de qualidade, tendo os seus egressos boa colocação no mercado de trabalho. (LIMA FILHO, 2002, p. 271)

Ao refletir acerca do processo de implementação da reforma, que acarretou transformação da identidade das instituições escolares, Ciavatta destaca que ela 
[...] certamente trouxe implicações para a identidade das escolas. Por ter sido um processo no qual as escolas tiveram que se inserir, sem a opção do contrário, suas identidades foram afrontadas por um projeto não construído por elas próprias, mas por sujeitos externos. A contradição vivida esteve na obrigação de apropriarem-se desse projeto como seu. (CIAVATTA, 2006, p. 9)

Cada instituição vivencia os processos de aplicação de uma legislação em função de suas características particulares, de seu contexto e da maneira como se dão as relações sociais em seu interior, o que significa dizer que a reforma ganhou sentidos próprios em diferentes contextos escolares.

No âmbito da ETF/Unidade Florianópolis, com base na leitura de registros institucionais e de entrevistas semi-estruturadas realizadas com educadores envolvidos com a reforma, verificouse um posicionamento inicial de enfrentamento, tendo em vista o desacordo de seus atores sociais com o princípio colocado pelo Decreto $N^{\circ} 2.208 / 97$, a separação obrigatória entre os cursos técnicos e o Ensino Médio, e também, por sua representação ideológica, de conduzir a formação profissional brasileira a um viés utilitário, centrado basicamente nas demandas do mercado.

Porém, após um processo de negação e enfrentamento, articulado pela atuação contundente de uma direção contrária aos preceitos da reforma, a Unidade foi vivenciando outros movimentos. Aos poucos a disposição de crítica às propostas reformistas foi dando lugar a negociações, tendo em vista a falta de recursos e a possibilidade de conquista de novas verbas, acenada pelo PROEP. A instituição, assim, foi se movimentando numa dinâmica de adesão, que Lima Filho caracteriza como sendo "[...] um processo de mediações que define a aplicação da reforma educacional em função das dinâmicas de aceitação e resistências internas e externas de cada instituição [...]" (2003, p. 77).

Nesse contexto, até 1999 a Unidade Florianópolis ainda ofereceu vagas para os cursos técnicos integrados, porém, no ano 2000 efetivou-se a separação dos cursos, com a oferta do Ensino Médio propedêutico e de cursos técnicos apenas nas modalidades sequencial e com concomitância interna, ou seja, para alunos do próprio Ensino Médio da Instituição, embora com poucas vagas para esta modalidade.

A manutenção dos cursos integrados até 1999 constituiu-se um ponto determinante de resistência da instituição à reforma, ainda que tenha se verificado um decréscimo significativo no número de vagas disponibilizadas aos egressos do Ensino Fundamental. No ano de 1998, a quantidade de vagas reservadas aos Cursos Técnicos Integrados na Unidade foi de 680 e em 2005, já sob o desenvolvimento do Ensino Médio, esse quantitativo foi de $320^{2}$ (47\%).

Os projetos dos novos cursos foram elaborados por comissões instituídas por portarias institucionais e, mesmo durante esse período, se constatou o desagrado de parte dos educadores, pois, para além da extinção dos cursos integrados, passava a ser desenvolvido um curso de Ensino Médio propedêutico, dentro de uma instituição de educação profissional, descaracterizando sua identidade.

\footnotetext{
${ }^{2}$ Relatórios de Gestão de 1999 e 2005.
} 


\section{A IMPLANTAÇÃO DA REFORMA NA VISÃO DOS EDUCADORES}

Anteriormente à Reforma, os cursos técnicos desenvolvidos na ETF/SC fundavam-se numa perspectiva de formação integral, com uma arquitetura curricular contemplando a integração entre a formação geral e a técnica.

Embora os reais motivos que levaram o governo federal a lançar mão de uma reforma estrutural na educação profissional não constituíssem unanimidade entre os professores, pelas entrevistas com educadores da instituição denota-se que entre o corpo docente prevalecia a visão do rompimento com a identidade institucional, construída historicamente e reconhecida socialmente, em função da oferta dos cursos técnicos integrados ao ensino médio.

"Uma das coisas que me preocupava muito, até por ter vivenciado aqui a questão do ensino integrado, [...] eu via a preocupação nessa mudança, de fazer uma coisa que a gente achava que fazia bem feito e que tinha tradição, para uma outra, que não sabia exatamente quais seriam as consequências."

Alguns educadores reforçaram a condição de descontentamento dos docentes quanto à cisão dos cursos técnicos em relação ao ensino médio, apregoada pela legislação reformadora.

"A visão que a gente tinha era de que o governo queria diminuir custos, isso era forte! [...] queria enfraquecer a educação profissional. [...] Era um tipo de política que tinha um viés de enfraquecer as instituições públicas. [...] Como não consegue terminar com as escolas técnicas federais, então era uma maneira de fragilizar."

Não obstante alguns entrevistados afirmem que a maioria do corpo docente tinha a percepção do panorama político-ideológico da reforma, outros reconhecem que, independentemente da prática docente realizada no contexto da sala de aula, parte dos docentes se mostrou um tanto ausente do processo, em termos de compreensão do contexto.

Em relação à percepção dos servidores administrativos acerca da reforma, constata-se que, de maneira geral, o coletivo não teve um engajamento tão expressivo no processo, restringindose aos envolvidos com os setores pedagógicos da instituição e também, de outros implicados com os movimentos coordenados pela seção sindical local que, em acompanhamento ao movimento nacional, inseria em suas pautas de reivindicações questões relativas à educação e formação de trabalhadores.

Acerca das posturas adotadas diante da reforma infere-se que se nos primeiros momentos a ETF-SC posicionou-se de forma intensamente adversa à sua implementação, em nova situação de gestão o discurso transportou-se para o imperativo da reforma, atribuindo ao MEC a determinação pela efetivação de seus preceitos e, trazendo para o contexto da escola, a reforma como possibilidade exclusiva para a educação profissional desenvolvida na Rede Federal. Lima Filho (2003) refere-se a esse processo de aderência às medidas da reforma como um processo de "adesão negociada".

Essa linha de argumentação foi destacada por alguns entrevistados referindo-se à fragilidade da direção em acatar os direcionamentos reformistas do MEC. Assim argumenta um educador entrevistado: "[...] essa foi a política adotada e, por incrível que pareça, nesse momento, pela fragilidade, a direção [...] efetivamente se aninhou, sem nenhum processo de enfrentamento, com a equipe da SEMTE, a Secretaria de Educação Média e Tecnológica." 
Pelos depoimentos verificou-se que os atores institucionais interagiram com a reforma por diferentes mediações, uns mais ativamente, outros de forma menos perceptível e outros até de não envolvimento, assinalando as saídas construídas pela instituição para materializar a reforma em função de suas características.

Nesse sentido, a cooptação da instituição para efetivar os princípios legais da Reforma da Educação Profissional foi possível dada à pressão do PROEP, que se constituiu em uma eficaz ferramenta utilizada pelo MEC, funcionando como uma compensação à progressiva diminuição de recursos para sustentação das atividades da escola. Sobre esse aspecto, um dos educadores assim argumentou:

\begin{abstract}
“O Decreto $N^{\circ} 2.208 / 97$ veio com força, não porque houve um aceite a suas concepções, mas ele veio com força porque veio acoplado a um sistema de financiamento do PROEP. [...] Não houve alternativas para os coordenadores de curso, senã entrarem com projetos para abrirem cursos do PROEP [...]. Ou aderem ou fecha o curso, ou não amplia. Essa era a perspectiva da nossa rede. [...] o PROEP deixava claro que os cursos para serem implantados tinham que ser sequenciais."
\end{abstract}

Outro interlocutor acrescentou: "Fomos obrigados por essa questão do PROEP! Houve um momento em que vimos que não teríamos mais dinheiro, e como é que se faz educação sem dinheiro? Ainda mais em uma instituição dessas."

Nesses termos, configurou-se a existência de duas redes educacionais paralelas, uma ocupada com a educação acadêmica, propedêutica, e outra vinculada à educação profissional, reforçando a dicotomia entre o pensar e o executar, entre a teoria e a prática. Produziu-se, nesse contexto, a ruptura entre educação regular e profissional, sendo esta, restringida a uma formação funcional direcionada fundamentalmente às demandas imediatas do mercado (LIMA FILHO, 2004) em detrimento de uma formação comprometida com a autonomia política dos trabalhadores.

Ao serem questionados sobre as condições efetivas que o MEC proporcionou aos educadores em âmbito nacional, foi unânime a visão de que os espaços de capacitação foram muito pontuais e que o processo foi construído e desenvolvido na esfera institucional.

Um ponto muito significativo na análise da implementação da reforma na Unidade Florianópolis, diz respeito à assimilação das questões pedagógicas que envolviam o processo. Em meio a todas as desconfianças que cercavam a construção dos novos currículos por competência, a partir dos espaços institucionais internos de capacitação e de construção dos currículos dos novos cursos técnicos de nível pós-médio, muitos educadores apropriaram-se dos novos conceitos que cercavam a reforma, especialmente no que se refere à construção de currículos a serem desenvolvidos por competências, o que foi se transformando em referência, utilizada pelo MEC em muitas instituições da Rede Federal.

Pode-se depreender que a influência dos trabalhos realizados na construção dos currículos na Unidade Florianópolis não se restringiu às instituições da Rede Federal, uma vez que ela pontuou, também, a rede estadual de educação, estendendo-se, inclusive, a instituições de outros países, como Chile, Bolívia e Paraguai, uma vez que os movimentos reformistas desse período não se circunscreveram ao espaço geográfico brasileiro, conforme elucidou um educador entrevistado:

\footnotetext{
"Apresentei como foi construído o nosso curso e o retorno que a gente tinha das pessoas que participavam era de que fazíamos um trabalho bem diferente. [...]
} 
Também tivemos umas viagens ao Mercosul. Num intercâmbio alguns participaram de encontros no Chile, Bolívia, Paraguai. Então nós éramos chamados porque fomos considerados referência."

Sobre as dinâmicas de implantação da reforma, os interlocutores salientam que o processo se construiu na prática dos grupos elaboradores dos novos cursos técnicos sequenciais e ensino médio propedêutico. De modo geral, os educadores que participaram desta pesquisa declaram não ter havido uma orientação comum na condução dos trabalhos. Pelas falas percebe-se a necessidade de linhas orientadoras para abalizar os trabalhos dos grupos, principalmente em relação à questão do currículo por competências e à avaliação que poderia ser desenvolvida dentro desse currículo.

"Nós fizemos por nós mesmos. Entramos nos grupos que elaboraram os novos currículos e fomos aprendendo a fazer juntos. Trocávamos ideias com pessoas de outros grupos e fomos fazendo como achávamos que deveria ser. Sempre nos baseávamos nas legislações e na experiência acumulada dos envolvidos. Só alguns meses depois, veio do MEC um documento apresentando os itens que deveriam compor os planos de curso."

Essa liberdade a princípio foi mal recebida entre os educadores por ter gerado muita insegurança, porém, num momento posterior agradou por possibilitar que cada equipe elaborasse os planos de cursos em conformidade com as expectativas e experiências dos grupos de professores que comporiam o corpo docente de cada curso. Entretanto, depois que os cursos começaram a ser desenvolvidos, a instituição deu-se conta de toda a diversidade pedagógica que compunha seu espaço. Sobre essa questão, um dos educadores assim se expressa: "[...] você já não tinha mais uma escola, mas quatro, cinco escolas."

Uma questão significativa no desenvolvimento dos novos planos de cursos foi a avaliação de que com as novas orientações sobre carga horária, os cursos ficaram muito enxutos, com pouco tempo para serem desenvolvidos os conteúdos considerados indispensáveis à formação técnica. Como as determinações para a Educação Profissional previam a possibilidade de certificações intermediárias, com vistas ao ingresso imediato no mercado de trabalho, houve a preocupação por parte de muitos docentes de que seria muito cedo para uma inserção na prática profissional, o que reforça a ideia da formação do trabalhador, centrada na lógica do mercado, compreendida por Kuenzer (1999) como propostas aligeiradas de formação profissional viabilizando o acesso a uma ocupação precarizada.

Acerca das modificações na prática docente em função da nova realidade de sala de aula imposta pela reforma, os educadores, de maneira geral, consideram que houve uma transformação positiva, pois os professores tiveram que rever suas práticas, já que os cursos passavam a atingir um alunado com perfil diferenciado. Os cursos integrados desenvolvidos anteriormente à reforma destinavam-se a jovens egressos do Ensino de $1^{\circ} \mathrm{Grau}$ e com as transformações curriculares o público alvo passou a ser composto por pessoas com ensino médio completo, muitos deles fora do contexto escolar há bastante tempo, o que pode ser constatado pela fala de um dos educadores: "Era clara a diferença de público. [...] Era comum eu ter alunos avós, [...] pessoas que estavam há 10, 15 anos sem estudar."

É importante ressaltar que a Unidade Florianópolis já vinha desenvolvendo cursos técnicos pós-médio desde o ano de 1990, paralelamente aos cursos integrados. Para o coletivo dos 
educadores da instituição, o desenvolvimento de cursos técnicos sequenciais ao ensino médio constituía-se em uma opção de inclusão da população com vistas à inserção no mundo do trabalho. Ou seja, a despeito da resistência à desvinculação dos cursos técnicos e ensino médio, para o conjunto dos educadores, havia na instituição condições para oferta de cursos pós-médio, o que foi reafirmado na elaboração do Plano Político Pedagógico da escola em 1996.

No que tange o desenvolvimento dos cursos por competência foram recorrentes as declarações acerca das deficiências e imprecisões sobre essa concepção, como evidenciado no depoimento a seguir:

\begin{abstract}
"Havia muitas dúvidas sobre como desenvolver um currículo por competências e principalmente sobre como avaliar os alunos nessa condição. Esse foi um ponto muito importante de embate e negação dos professores, especialmente os da formação geral, que elaboraram o projeto do Ensino Médio. A questão das competências foi totalmente rechaçada por esse grupo de docentes. Foi opinião geral entre eles! Mas, como a reforma foi imposta à toda a instituição, também o ensino médio propedêutico teve que se adaptar."
\end{abstract}

Porém, alguns grupos, na elaboração dos novos cursos, assumiram a introdução do modelo de competências como um aspecto positivo da reforma.

Finalmente, sobre o conjunto das transformações que ocorreram na instituição em face da Reforma da Educação Profissional instituída pelo Decreto $N^{\circ} 2.208 / 97$, constata-se que uma das mais significativas tenha sido pertinente às mudanças nas relações que se estabeleciam no contexto institucional. Mediante prática autoritária, a reforma impôs ao cotidiano da escola uma separação de atuação e, mais que isso, de convívio, entre os docentes da formação geral e os da formação técnica. Toda a riqueza pedagógica gerada pela interação entre esses docentes foi restringida, tendo em vista que cada grupo ocupou-se, daquele momento em diante, dos assuntos e atividades exclusivos de seu curso.

Um dos depoimentos faz referência a essa questão:

“[...] Existia uma integração efetiva pela convivência, porque integração se dá não só pelo projeto do curso, mas pelo convívio, pela troca de ideias. [...] A dinâmica de convivência era bastante forte naquele momento e com o Decreto $N^{\circ} 2.208 / 97$ não se estabeleceu mais esse diálogo [...]."

Assim, a partir da implantação da reforma, o ambiente institucional caracterizou-se por grupos desconectados e com poucos interesses comuns, situação quebrada apenas pela iniciativa de aproximações pontuais na busca de troca de experiências entre os grupos elaboradores dos planos dos novos cursos.

\title{
5 CONSIDERAÇÕES FINAIS
}

Para dar consecução à Reforma da Educação Profissional, o MEC utilizou-se de amplo aparato jurídico, principalmente o Decreto $N^{\circ} 2.208 / 97$, que desvinculou os cursos técnicos do Ensino Médio. A extinção dos cursos técnicos integrados constituiu-se o ponto forte da reforma, impactando severamente as instituições da Rede Federal e abalando a identidade dessas instituições. 
Observam-se diferenças entre o que foi idealizado em termos de reforma pelo MEC, a materialização de seu aparato normativo e sua efetivação no espaço educativo, o que compreende as consequências do processo de aplicação das políticas educacionais no cotidiano institucional, relacionando as condições das políticas e suas implicações nas práticas curriculares e docentes. É preciso, pois, ressaltar a ponderação acerca das nuances entre os discursos oficiais que geram a reforma e a realidade de sua consolidação nos espaços educativos.

No contexto da Unidade Florianópolis da ETF/SC constatou-se que a instituição vivenciou diferentes movimentos durante a reforma, primeiro de resistência e, após, de adesão por pressões envolvendo recursos financeiros, podendo ser consideradas marcas institucionais frente à Reforma a oferta do ensino médio propedêutico e a resistência à extinção imediata dos cursos técnicos integrados.

Num panorama diferenciado de envolvimento dos educadores da instituição com a reforma, é possível apreender que alguns grupos envolvidos com a reestruturação ou construção de novos modelos curriculares apropriaram-se de conceitos embutidos na referida reforma, especialmente em relação ao desenvolvimento do currículo por competências, transformando totalmente o curso, enquanto outros simplesmente efetivaram acomodações curriculares para atendimento aos preceitos da legislação reformadora.

Por fim, observa-se que o coletivo da instituição vivenciou um processo heterogêneo, que por diferentes caminhos foi dando contornos à reforma nos cursos técnicos desenvolvidos pela Unidade Florianópolis - ETF/SC.

\section{REFERÊNCIAS BIBLIOGRÁFICAS}

1. BRASIL. MEC. Política e resultados 1995-2002: a Reforma da Educação Profissional. Brasília. 2002.

2. CNE/CEB. Resolução №4 de 08 de dezembro de 1999. Institui as Diretrizes Curriculares Nacionais para a Educação Profissional de Nível Técnico. Brasília. 1999.

3.

Decreto $\mathbf{N}^{\circ} \mathbf{2 . 2 0 8}$ de 17 de abril de 1997. Regulamenta o $\S 2$ 20 do art. 36 e os arts. 39 a 42 da Lei Federal № 9.394/96, que estabelece as Diretrizes e Bases da Educação Nacional. 1997.

4. CIAVATTA, Arquivos da memória do trabalho e da educação e formação integrada. IV Congresso Brasileiro de História da Educação. Goiânia/GO. 2006. Disponível em http://www.sbhe.org.br/novo/congressos/cbhe4/individuais-coautorais/eixo07/Maria\% 20Ciavatta \%20-\%20Texto.pdf.

5. FRIGOTTO, Gaudêncio. A nova e a velha faces do capital e o labirinto dos referenciais teóricos. In: FRIGOTTO, Gaudêncio; CIAVATTA, Maria. (orgs) Teoria e educação no labirinto do capital. Petrópolis/RJ. Vozes, 2001.

6. __ Gaudêncio; CIAVATTA, Maria. A formação do cidadão produtivo: a cultura de mercado no ensino médio técnico. Instituto Nacional de Estudos e Pesquisas Educacionais Anísio Teixeira. Brasília, 2006.

7. KUENZER, Acácia Z. A reforma do ensino técnico e suas consequências. In: Educação profissional: tendências e desafios. Documento final do Segundo Seminário sobre reforma do 
ensino profissional. Curitiba: SINDOCEFET/PR, 1999.

8. LIMA FILHO, Domingos Leite. Impactos das recentes políticas públicas de educação e formação de trabalhadores:desescolarização e empresariamento da educação profissional. PERSPECTIVA, Florianópolis/SC, v.20, n.02, p. 269-301, jul./dez. 2002.

9. ___ Domingos Leite. A desescolarização da escola. Impactos da reforma da educação profissional (período 1995 a 2002). Curitiba: Torre de Papel. 2003.

10. Domingos Leite. Dimensões e limites da globalização. Petrópolis/RJ. Vozes, 2004.

11. MARIUZZO, Patrícia. Socióloga discute o desemprego e a questão de gênero no mundo do trabalho. Entrevista concedida por Helena Hirata. Inovação Uniemp. Vol. 2, n.5, Campinas/SP, nov. 2006.

12. RAMOS, Marise Nogueira. O público e o privado na educação profissional: as políticas do MEC. In: ADRIÃO, Theresa; PERONI, Vera. (orgs.) 0 público e o privado na educação: Interfaces entre os estado e a sociedade. São Paulo. Xamã, 2005.

13. Marise Nogueira. A pedagogia das competências: autonomia ou adaptação? São Paulo: Cortez, 2001. 